\title{
Psychosocial support and parents' social life determine the self-esteem of orphan children
}

This article was published in the following Dove Press journal:

Risk Management and Healthcare Policy

13 October 2015

Number of times this article has been viewed

\author{
Markos Abiso Erango' \\ Zikie Ataro Ayka ${ }^{2}$ \\ 'School of Mathematical and \\ Statistical Sciences, Department of \\ Applied Statistics, Hawassa University, \\ Hawassa, ${ }^{2}$ Department of Biology, \\ Arba Minch University, Arba Minch, \\ Ethiopia
}

\begin{abstract}
Parental death affects the life of children in many ways, one of which is self-esteem problems. Providing psychosocial support and equipping orphans play a vital role in their lifes. A cross-sectional study was conducted on 7-18-year-old orphans at 17 local districts of Gamo Gofa Zone, Southern Regional State of Ethiopia. From a total of 48,270 orphans in these areas, 4,368 were selected using stratified simple random sampling technique. Data were collected with a designed questionnaire based on the Rosenberg's rating scale to measure their self-esteem levels. Self-esteem with a score less than or equal to an average score was considered to be low self-esteem in the analysis. Binary logistic regression model was used to analyze the data using the SPSS software. The results of the study revealed that the probability of orphans suffering from low selfesteem was 0.59 . Several risk factors were found to be significant at the level of $5 \%$. Psychosocial support (good guidance, counseling and treatment, physical protection and amount of love shared, financial and material support, and fellowship with other children), parents living together before death, strong relationship between parents before death, high average monthly income, voluntary support, and consideration from the society are some of the factors that decrease the risk of being low in self-esteem. There are many orphans with low self-esteem in the study areas. The factors negatively affecting the self-esteem of orphans include the lack of psychosocial support, poor social life of parents, and death of parents due to AIDS. Society and parents should be aware of the consequences of these factors which can influence their children's future self-esteem.
\end{abstract}

Keywords: psychosocial support, logistic regression, orphan, self-esteem

\section{Background}

Psychosocial support is a scale of care and support, which influences both the individual and the social environment in which people live. It not only ranges from the care and support offered by caregivers, family members, friends, neighbors, teachers, health workers, and community members on a daily basis but also extends to those offered by specialized psychological and social services. Psychosocial support can provide the opportunity for the children to develop skills in order to adjust their life. Traditionally, children have been the central focus in the society; hence, their protection has been rendered an issue of particular concern to the whole community. ${ }^{1}$ However, in developing countries, the number of children orphaned by AIDS is growing rapidly. Consequently, the psychological problems of these children is a serious socioeconomic and developmental challenge that may affect the development of developing countries. Orphan hood is frequently accompanied by multidimensional problems including prejudice, reduced access to health and school services, inadequate food, and sexual abuse, which can jeopardize children's prospects of completing school. ${ }^{2,3}$ Similarly, according to the study by Nyamukapa et al, ${ }^{4}$
Correspondence: Markos Abiso Erango School of Mathematical and Statistical Sciences, Hawassa University, PO Box 05 , Hawassa, Ethiopia

Email markos.erango73@gmail.com 
in Eastern Zimbabwe, orphans were found to suffer greater psychological distress than nonorphans. Masuka et al ${ }^{5}$ reported that orphans have the potential to develop their abilities and play a significant role in the society. But they face relentless struggles for physical survival, basic education, love and affection, and protection against exploitative abuse and discrimination. According to Levine et al, ${ }^{6}$ age, sex, socioeconomic status, body image, family relation, peer relations, and social inequality are factors affecting the development of self-esteem. Many studies report that loss of one or both parents from AIDS confronts the child with immense psychological and social problems, such as stigmatization, discrimination, exploitation, emotional neglect, and psychological distress. ${ }^{7,8}$ Baumeister et $\mathrm{al}^{9}$ stated that a healthy self-esteem is strongly associated with happiness and confidence, and is moderately related with academic performance.

Rosenberg and Owens ${ }^{10}$ reported that a healthy self-esteem is an important variable in protecting these children against secondary problems, such as depression, lack of motivation, dropping out of school, and engaging in risky behaviors. According to the report by the World Health Organisation, ${ }^{11}$ psychosocial support plays a vital role in mental health promotion, can assist greatly in developing personality by enhancing life skills - such as cognitive functioning, help to develop positive self-esteem, provide social and personal problem-solving skills, and provide the ability to manage major changes and stresses in life. It also entails the positive influence on the social environment, as well as the ability to work productively and fruitfully and to contribute to the community. Providing psychosocial care for orphan and vulnerable children in the form of food, daytime shelter, protection from unfavorable social and physical environments create a sense of security, belongingness, and stability in their lives and is one of the urgent solutions that determine the self-esteem of orphans and provide productive, effective, and fruitful future generations in the community. ${ }^{12-14}$ Social protection can be found in three pillars, such as social security, income security, and social safety nets. ${ }^{15,16}$ Devereux and Sabates-Wheeler ${ }^{15}$ defined social protection as the total public and private initiatives that provide income or consumption transfers to the poor, protect the vulnerable against livelihood risks, and enhance the social status and rights of the marginalized.

Unhealthy parental social life and lack of psychosocial care and social protection are causes of low self-esteem and a poor quality of life of orphan children, which deserve further investigation. Thus, the main objective of this study was to assess the factors that determine the self-esteem of orphan children.

\section{Methods}

The study population consisted of 48,270 orphans whose age ranged from 7 to 18 years and were residing in one the 17 local districts of Gamo Gofa Zone in the Southern Nations, Nationalities, and Peoples' Region, Ethiopia. A cross-sectional survey was conducted with a stratified random sampling technique on 4,368 samples from the total population. The sample size $(4,368)$ was determined with appropriate derivations. Data were collected using a designed questionnaire based on Rosenberg's self-esteem scale that measures the self-esteem levels of the respondents. ${ }^{10,17}$

The response variable was an aggregate measure of the self-esteem of an orphan. It is dichotomized as low selfesteem (coded as 1) if his/her test score was less than or equal to the average test score and as high self-esteem (coded as 0 ) if the test score was greater than the average score, based on Rosenberg's self-esteem scale.

The explanatory variables, such as age of child, father's education, mother's education, father's occupation, mother's occupation, parents' living conditions before death, the strength of relationship between parents before death, good guidance, counseling and treatment, average monthly income, deceased parents, cause of death, change in home circumstances, housing ownership, residence of child, physical protection and amount of love shared, fellowship with other children, voluntary support, and consideration from the society, financial and material support, are the potential risk factors considered in this study. The research proposal for this study was checked and approved by ethical clearance committee of Arba Minch University and hence, ethical clearance was given for the research on orphan children in the study area. Consent was given by the guardians of the children for them to be included in the study. The caretakers were also included in responding some of the questions.

\section{Logistic regression model}

The response variable is the self-esteem status of an orphan, denoted by $Y$, which is dichotomous with outcome either low selfesteem (1) with probability $p_{i}=P\left(Y_{i}=1 \mid X\right)$, or high self-esteem (0) with probability $1-p_{i}=P\left(Y_{i}=0 \mid X_{i}\right)$, where $X_{i}$ is a vector of $r$ factors or predictors for each orphan $i=1,2,3, \ldots, \mathrm{n}$.

The logistic regression model is given ${ }^{18}$ as

$$
p_{i}=\frac{e^{\beta_{0}+\beta_{1} X_{i 1}+\ldots+\beta_{r} X_{i r}}}{1+e^{\beta_{0}+\beta_{1} X_{i 1}+\ldots+\beta_{r} X_{i r}}}
$$

and equivalently expressed with the logit link function as

$$
\log \operatorname{it}\left(p_{i}\right)=\beta_{0}+\beta_{1} X_{i 1}+\ldots+\beta_{r} X_{i r}
$$


where $i=1,2,3, \ldots, n ; j=0,1,2,3, \ldots, r ; X_{i j}$ is the $j$ th predictor of the $i$ th child; $\beta_{0}$ is an intercept; and $\beta_{j}$ s are coefficients of the predictor variables.

\section{Estimation of the parameters}

The likelihood function $L(y \mid X, \beta)$ is defined as the joint probability distribution $f(y \mid X, \beta)$ of the independent observation vector of size $\mathrm{n}$ given the regression parameters $\beta$ and the design matrix $X$. The likelihood function with the $n$ independent observations is expressed as

$$
\begin{aligned}
& L(y \mid X, \beta) \\
& \quad=\prod_{i=1}^{n}\left(\frac{e^{\beta_{0}+\beta_{1} X_{i 1}+\ldots+\beta_{r} X_{i r}}}{1+e^{\beta_{0}+\beta_{1} X_{i 1}+\ldots+\beta_{r} X_{i r}}}\right)^{y_{i}}\left(\frac{1}{1+e^{\beta_{0}+\beta_{1} X_{i 1}+\ldots+\beta_{r} X_{i r}}}\right)^{1-y_{i}}
\end{aligned}
$$

It refers to how likely a particular population is to produce an observed sample given the parameter values. The estimation of parameters is based on the maximum likelihood method, with Newton-Raphson iterative search algorithm to maximize the likelihood function or its logarithmic transformation. ${ }^{18}$

\section{Results and discussion}

Among the 4,368 samples considered, 52.2\% were females and $47.8 \%$ were males. Approximately $40.98 \%$ of the orphans' mothers only were deceased; $37 \%$ of orphans' fathers only were deceased, and $22.02 \%$ of the orphans had lost both parents. The analysis showed that the occurrence of low self-esteem among the orphans was 59\%. Only $41 \%$ of them were of high self-esteem. Approximately $25.64 \%$ had lost a parent due to AIDS. Additionally, the analysis indicates that among the sampled orphans only $40 \%$ got consideration from the society, $27 \%$ got some level of voluntary support, $20 \%$ got physical protection and amount of love shared by others, and $35 \%$ got some financial and material support for their education and daily life.

Tests to find out the association between the child's self-esteem status and the factors were carried out using the chi-square tests. All the factors were significantly associated with the self-esteem status of a child at the significant level of $5 \%$. The results are displayed in Table 1 .

To check the goodness-of-fit of the model, the HosmerLemeshow test was used. ${ }^{19}$ The chi-square test statistic value was $\left(\chi^{2}=6.329\right)$, with 8 degrees of freedom $(d f)$ at the significant level of 0.61 . Hence, there was not enough evidence to reject the null hypothesis that the model fits the data. Moreover, the likelihood ratio test (deviance) was applied
Table I Tests of association of predictor variables on the self-

\begin{tabular}{|c|c|c|c|}
\hline \multirow[t]{2}{*}{ Predictor variable } & \multicolumn{3}{|c|}{ Self-esteem status } \\
\hline & Chi-square & $d f$ & $P$-value \\
\hline Age of child & 20.5 & 2 & 0.002 \\
\hline Father's education level & 39.8 & I & 0.000 \\
\hline Mother's education level & 47.00 & I & 0.000 \\
\hline Occupation of father & 55.98 & 4 & 0.000 \\
\hline Occupation of mother & 18.3 & 4 & 0.000 \\
\hline Average monthly income & 186.45 & 2 & 0.000 \\
\hline Voluntary support & $\mid 4.4573$ & I & 0.000 \\
\hline Consideration from the society & 7.0413 & I & 0.003 \\
\hline Financial and material support & 12.0746 & I & 0.004 \\
\hline Parents' living condition before death & 96.13 & 2 & 0.000 \\
\hline $\begin{array}{l}\text { Strength of parents relationship } \\
\text { before death }\end{array}$ & 157.05 & I & 0.000 \\
\hline Deceased parents & 54.42 & 2 & 0.000 \\
\hline Cause of death & 75.20 & I & 0.000 \\
\hline $\begin{array}{l}\text { Physical protection and amount } \\
\text { of love shared }\end{array}$ & 70.54 & I & 0.000 \\
\hline Fellowship with other children & 11.5 & I & 0.002 \\
\hline Change in home circumstance & 123.32 & I & 0.000 \\
\hline Residence of child & 7.382 & I & 0.007 \\
\hline $\begin{array}{l}\text { Housing ownership (private, rented, } \\
\text { and other) }\end{array}$ & 64.74 & 3 & 0.000 \\
\hline $\begin{array}{l}\text { Good guidance, counseling, } \\
\text { and treatment }\end{array}$ & 18.5 & I & 0.000 \\
\hline
\end{tabular}
esteem status of orphan children

Abbreviation: $d f$, degrees of freedom.

to test the difference between the null and the final model, with the results of $-2 \log$ likelihood to be 840.70 for the null model and 245.43 for the final model. The likelihood ratio test is 595.27 with a $10 d f$.

Results of the logistic regression analysis are displayed in Table 2. The factors such as consideration from the society, voluntary support, physical protection and amount of love shared, financial and material support, number of parents dead, cause of parent's death, average monthly income, change in home circumstances, strength of relationship between parents, and parents' living conditions before death had significant effect on the self-esteem of the orphans.

The odds ratios can be interpreted as follows: For a child that did not get the expected consideration from the society, the odds ratio of self-esteem is 1.76 times lower than that of those receiving better consideration and care from society. Similarly, the lack of voluntary support increased the odds ratio by 3.4 times; lack of physical protection and amount of love shared increased the odds ratio by 1.06 times; lack of financial and material support from the community increased the odds ratio by 1.22 times; and weak relationship between parents before death increased the odds ratio by 3.11 times. Moreover, the odds ratio low self-esteem was decreased by $84.6 \%$ for a child that lost its mother only and by $67.9 \%$ 
Table 2 Multivariate analysis of logistic regression model

\begin{tabular}{|c|c|c|c|c|c|c|c|}
\hline Predictor & Category & $\hat{\beta}$ & $\operatorname{SE}(\hat{\beta})$ & Wald & $d f$ & $\begin{array}{l}\text { P-value } \\
\text { (Significance) }\end{array}$ & $\operatorname{Exp}(\hat{\beta})$ \\
\hline Constant & & -1.97 & 0.080 & 609.47 & 1 & 0.05 & 0.139 \\
\hline \multirow[t]{3}{*}{ Age of child, years } & $15-18$ & - & - & 11.983 & 1 & 0.05 & \\
\hline & $11-14$ & 0.569 & 0.388 & 2.147 & 1 & 0.143 & 1.767 \\
\hline & $7-10$ & 0.184 & 0.322 & 0.336 & 1 & 0.001 & 1.202 \\
\hline Consideration from & Yes $(0)$ & - & - & - & - & - & - \\
\hline the society & No (I) & 1.03 & 0.423 & 5.55 & 1 & 0.018 & 1.76 \\
\hline \multirow[t]{2}{*}{ Voluntary support } & Yes $(0)$ & - & - & - & - & - & - \\
\hline & No (I) & 1.231 & 0.50 & 6.08 & 1 & 0.014 & 3.4 \\
\hline \multirow[t]{3}{*}{ Deceased parents } & Both (0) & - & - & 10.97 & 2 & 0.001 & \\
\hline & Mother (I) & -1.9 & 0.596 & 11.02 & 1 & 0.001 & 0.154 \\
\hline & Father (2) & -1.3 & 0.59 & 5.04 & 1 & 0.003 & 0.321 \\
\hline \multirow[t]{2}{*}{ Cause of death } & Non-AIDS (0) & - & - & - & & - & - \\
\hline & AIDS (I) & 1.31 & 0.403 & 10.940 & I & 0.000 & 1.58 \\
\hline \multirow[t]{3}{*}{ Average monthly income } & High (0) & - & - & 11.97 & 2 & 0.001 & \\
\hline & Medium (I) & -0.002 & 0.001 & 20.49 & 1 & 0.000 & 1.16 \\
\hline & Low (2) & -0.05 & 0.60 & 5.70 & 1 & 0.003 & 1.69 \\
\hline Physical protection and & Yes $(0)$ & - & - & & & & \\
\hline amount of love shared & No (I) & 0.06 & 0.59 & 0.01 & 1 & 0.000 & 1.06 \\
\hline Financial and material & Yes $(0)$ & - & - & & & & \\
\hline support & No (I) & 0.98 & 0.50 & 6.01 & I & 0.011 & 1.22 \\
\hline Effect of change in home & Yes (0) & - & - & & & & \\
\hline circumstances & No (I) & 0.38 & 0.64 & 0.33 & I & 0.252 & 1.33 \\
\hline Strong relationship between & Yes $(0)$ & - & - & & & & \\
\hline parents before death & No (I) & 1.136 & 0.0341 & 11.094 & I & 0.000 & 3.11 \\
\hline Parents' living condition & Together $(0)$ & - & - & 33.69 & 2 & 0.000 & \\
\hline \multirow{2}{*}{ before death } & Separated (I) & 0.105 & 0.65 & 0.01 & I & 0.000 & 1.039 \\
\hline & Divorced (2) & 0.42 & 0.71 & 0.40 & 1 & 0.031 & 1.37 \\
\hline
\end{tabular}

Note: -'s and parenthesis indicate the reference category.

Abbreviations: $d f$, degrees of freedom; SE, standard error; N/A, not applicable.

for those that lost only their father as compared to those that lost both parents, where other factors controlled. This indicates that orphans who have lost both parents are the most affected. Losing a father induces more risk of being low self-esteem than losing a mother, with a difference of as much as $16.7 \%$.

For an orphan who lost his/her parents due to AIDS, the odds ratio of developing low self-esteem was increased by $58 \%$ as compared to that whose parents' death was due to non-AIDS causes. The odds ratio of being low in self-esteem, for a child who has low average monthly income and medium income, is 1.69 times, 1.16 times that with a high average monthly income. Economic status of the parents could positively affect the self-esteem development of a child.

The synchronization of parents matters. Compared to a child from parents living together before death, the odds ratio of being low self-esteem was increased by $3.9 \%$ for a child with separated parents and increased by $37 \%$ for that with divorced parents. Divorcing parents were found to be the biggest risk for the child to be affected by low self-esteem.
Thus, it is interesting to find that the increased risk of low self-esteem was due to factors, such as death of both parents, parents' death due to AIDS, low average monthly income, lack of consideration from the society, lack of physical protection and amount of love shared from community, lack of financial and material support, change in home circumstance, weak relationship between parents before death, and parents not living together before death.

\section{Conclusion}

The aim of this study was to determine the factors that may account for changes in the self-esteem of 7-18-year-old orphan children. The results of this study revealed that the prevalence of low self-esteem among orphans was 59\%, which is high.

From the logistic model analysis, eleven risk factors were found to be significant at the level of 5\%. Increased odds ratio of risk-to-low self-esteem was due to the lack of consideration from the society, lack of voluntary support, absence of physical protection and love, lack of financial and material support, living conditions of parents before death, 
weak relationship between parents before death, low average monthly income, death of both parents due to AIDS, change in home circumstance, and the age of the child itself.

In conclusion, a significant number of orphans are found to be of low self-esteem, and so they need greater attention. The factors negatively affecting self-esteem of the orphans mainly include the unhealthy parental social life, and lack of psychosocial and voluntary support from the society. Society should be aware of the consequences of decisions they make about their health and social life impacting on their children's future self-esteem and the importance of psychosocial support in the life of orphans. Based on the identified risk factors, appropriate interventions need to be implemented to mitigate the challenges so as to maintain normal self-esteem developments.

\section{Acknowledgments}

The authors would like to thank the anonymous reviewers for their comments that were useful to improve the write-up of the paper and Arba Micnh University research office for financial support.

\section{Disclosure}

The authors report no conflicts of interest in this work.

\section{References}

1. Mushunje MT. Child protection in Zimbabwe: yesterday, today and tomorrow. J Soc Dev. 2006;21(1):12-34.

2. Smart R. Policies for orphans and vulnerable children: a framework for moving ahead; 2008. Available from: http://www.policyproject.com. Accessed Sep 2013.

3. UNAIDS. Report on the global AIDS epidemic, Switzerland, WHO Library Cataloguing, in publication data; 2008. Available from: http:// www.unaids.org. Accessed September 19, 2009.
4. Nyamukapa CA, Gregson S, Lopman B, Saito S, Watts H. AIDS care: psychological and socio-medical aspects of AIDS/HIV causes and consequences of psychological distress among orphans in eastern Zimbabwe. AIDS Care. 2010;22(8):988-996.

5. Masuka, T, Banda RG, Mabvurira V, Frank R. Social protection programmes for orphans and vulnerable children (OVC) in Zimbabwe. International Journal of Humanities and Social Science. 2012;2(12):59-66.

6. Levine C, Foster G, Williamson J. Children on the Brink. Joint Reports of New Orphans Estimate - A Frame Work for Action. New York: UNCIF; 2004.

7. Barber CN, Ball J, Armistead L. Parent-adolescent relationship and adolescent psychological functioning among African-American female adolescents: self-esteem as a mediator. J Child Family Stud. 2003;12(3): 361-374.

8. Xiaoming L. Psychopathological developmental framework. J Assoc Nurses AIDS Care. 2008;19(2):147-157.

9. Baumeister RF, Campbell JD, Krueger JI, Vohs KD. Does high selfesteem cause better performance, interpersonal success, happiness, or healthier lifestyles? Psychol Sci Public Interest. 2003;4(1):1-44.

10. Rosenberg M, Owens TJ. Low self-esteem people. In: Owens TJ, Stryker S, Goodman N, editors. Extending Self-esteem Theory and Research. Cambridge: Cambridge University; 2001;400-436.

11. WHO. Improving outcomes in depression. The whole process of care needs to be enhanced. BMJ. 2001;323(7319):948-949.

12. Baron R, Kalsher J. Psychology from Science to Practice. 2nd ed. Boston: Allyn and Bacon; 2008.

13. Santrock WJ. Psychology. 7th ed. New York: McGraw Hill; 2003.

14. Gandure S. Baseline Study of Social Protection in Zimbabwe, A Report Prepared for the Social Protection Technical Review Group (SPTRG) of the Multi-Donor Trust Fund; 2009:17.

15. Devereux S, Sabates-Wheeler R. Transformative social protection. IDS Working, Paper 232; 2004. Available from: http://www.ids.ac.uk/ is/bookshop/wp/wp232.pdf. Accessed October, 2014.

16. UNICEF. Comparing child well-being in OECD countries: concepts and methods; 2007. Available from: http://www.unicef-irc.org/publications. Accessed October 26, 2013.

17. Rosenberg M. Society and the Adolescent Self-image. Princeton, NJ: Princeton University Press; 1965.

18. Agresti A. An Introduction to Categorical Data Analysis. 3rd ed. New York: John Wiley and Sons Inc.; 1996.

19. Hosmer DW, Lemeshow S. Applied Logistic Regression. 3rd ed. New York: John Wiley and Sons Inc.; 1989.
Risk Management and Healthcare Policy

\section{Publish your work in this journal}

Risk Management and Healthcare Policy is an international, peerreviewed, open access journal focusing on all aspects of public health, policy, and preventative measures to promote good health and improve morbidity and mortality in the population. The journal welcomes submitted papers covering original research, basic science, clinical \& epidemio-

\section{Dovepress}

logical studies, reviews and evaluations, guidelines, expert opinion and commentary, case reports and extended reports. The manuscript management system is completely online and includes a very quick and fair peerreview system, which is all easy to use. Visit http://www.dovepress.com/ testimonials.php to read real quotes from published authors. 